\title{
SISTEM PENDUKUNG KEPUTUSAN PEMILIHAN KENDARAAN DALAM MENDISTRIBUSIKAN ZAKAT, INFAK DAN SEDEKAH
}

\author{
Emi Suryadi \\ Magister TeknikInformatikaSTMIK AMIKOM Yogyakarta \\ E-mail: emisuryadi@gmail.com
}

Diterima: 8 Juli 2016/ Disetujui: 22 Juli 2016

\begin{abstract}
Decision support systems into a solution in deciding the problem of various election BAZNAS vehicles in the city of Mataram. Various types of vehicles available in the office BAZNAS Mataram, this can help in the process of decision-support of various criteria and the selected alternative. The results of data collection and calculation processes Analytic Hierarchy Process (AHP) to get the value on which to base recommendations for the selection of vehicles in the city of Mataram BAZNAS namely deer with a total value of 0.4998097. The highest value is the value of the selected vehicle that can be used in distributing Zakat, Infak and Sedekah to various areas in the city of Mataram. The result of this decision in accordance with the calculation criteria and alternatives on which to base the selection of vehicles in the city of Mataram BAZNAS Office in choosing a vehicle. Zakat, Infakand Sedekah distributed to the poor are earning less than the average and for the people of the poor and orphans so that it can be utilized for the welfare of society, especially in the city of Mataram.
\end{abstract}

Keywords: Decision support system, BAZNAS Mataram, AHP, Zakat, Infak andSedekah.

\begin{abstract}
Abstrak
Sistem pendukung keputusan menjadi solusi dalam memutuskan problem dari berbagai pemilihan kendaraan di BAZNAS kota Mataram. Berbagai jenis kendaraan yang ada di kantor BAZNAS Kota Mataram, hal ini dapat membantu dalam proses pendukung pengambilan keputusan dari berbagai kriteria dan alternatif yang dipilih. Hasil pengumpulan data dan proses perhitungan metode Analytic Hierarchy Process (AHP) mendapatkan nilai yang menjadi dasar rekomendasi dalam pemilihan kendaraan di BAZNAS Kota Mataram yaitu Kijang dengan nilai total 0.4998097. Nilai yang tertinggi merupakan nilai kendaraan terpilih yang dapat digunakan dalam mendistribusikan Zakat, Infak dan Sedekah ke berbagai wilayah yang ada di Kota Mataram. Hasil keputusan ini sesuai dengan perhitungan kriteria-kriteria dan alternatif yang menjadi dasar pemilihan kendaraan yang ada di Kantor BAZNAS Kota Mataram dalam memilih kendaraan. Zakat, Infak dan Sedekah disalurkan kepada masyarakat yang kurang mampu yaitu yang berpenghasilan di bawah rata-rata dan bagi masyarakat fakir miskin dan anak yatim sehingga hal ini dapat dimanfaatkan untuk kesejahteraan masyarakat khususnya yang ada di wilayah Kota Mataram.
\end{abstract}

Kata Kunci: Sistem pendukung keputusan, BAZNAS kota Mataram, AHP, Zakat, Infak dan

\section{PENDAHULUAN}

Sistem pendukung keputusan dapat membantu menentukan pilihan dari berbagai jenis pilihan yang ada. Hal ini dapat membantu Badan Amil Zakat Nasional (BAZNAS) Kota Mataram dalam pendistribusian zakat, infak dan sedekah, sesuai dengan peraturan daerah Kota Mataram Nomor 1 tahun 2015 pasal 11 yang berbunyi, BAZNAS Kota merupakan lembaga yang berwenang melakukan tugas pengelolaan zakat, infak dan sedekah di tingkat Kota. Pendistribusian zakat, infak dan sedekah ke setiap daerah yang ada di Kota Mataram tentunya membutuhkan prasarana seperti kendaraan yang sesuai. Kendaraan merupakan alat transportasi yang digunakan manusia melakukan aktifitas atau kegiatannya untuk berpindah dari titik satu ke titik tujuannya. 
Mobil dan motor adalah salah satu contoh kendaraan yang umum digunakan dalam mendistribusikan zakat, infak dan sedekah untuk masyarakat yang kurang mampu dari segi pertama, para pekerja harian yang penghasilannya di bawah rata-rata. Kedua, pendistribusian yang dilakukan bagi masyarakat fakir miskin dan anak yatim di wilayah Kota Mataram. Pemilihan kendaraan yang tepat dan sesuai dengan kriteria beban yang diangkat utuntuk mendistribusikan zakat, infak dan sedekah di wilayah Kota Mataram setidaknya mancakup kriteria seperti, biaya operasional kendaraan, tahun kendaraan, kondisi kendaraan, volume penggunaan kendaran dan performa kendaraan. Menyelesaikan problem ini, tentunya membutuhkan pendukung keputusan sehingga dapat membantu pengawai BASNAS Kota Mataram dalam menentukan kendaraan yang baik untuk mendistribusikan zakat, infakdan sedekah ke setiap daerah. Pengambilan keputusan dalam kasus ini menggunakan Analitycal Hierarchi Process (AHP). AHP merupakan suatu metode pengambilan keputusan untuk menyelesaikan permasalahan yang kompleks dimana data dan informasi statistic tersedia sangat sedikit (Saaty, 1980).

\section{METODE PENELITIAN}

Metode yang digunakan dalam penelitian ini adalah metode Action Research, dimana Action Research merupakan penelitian yang berfokus langsung pada tindakan social. (Menurut Hasibuan, 2007). Pengumpulan data pada penelitian ini dengan melakukan wawancara dengan Pengawai BAZNAS Kota Mataram, serta melakukan observasi dilingkungan BAZNAS Kota. Data yang diperoleh diolah agar dapatmemperolehhasil dalam penelitian. Proses pengolahan in imerupakan salah satu proses penelitian yang dilakukan setelah semua data yang diperlukan guna memecahkan permasalahan yang diteliti sudah diperoleh secara lengkap. Ketajaman dan ketepatan dalam penggunaan alatanalisis sangat menentukan keakuratan pengambilan keputusan, karena itu kegiatan analisis data merupakan kegiatan yang tidak dapat diabaikan begitu saja dalam proses penelitian. Kesalahan dalam menentukan alat analisis dapat berakibat fatal terhadap kesimpulan yang dihasilkan dan hal ini akan berdampak lebih buruk lagi terhadap penggunaan dan penerapan hasil penelitian.

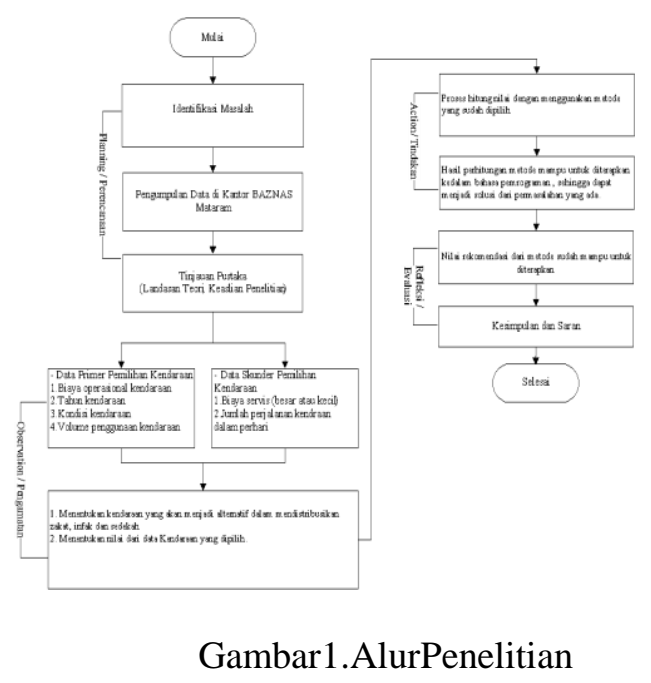

Alur penelitian ini pertama kali mengidentifikasi permasalahan menjadi dasar penelitian, serta mengumpulkan data-data yang terkait dengan penelitian di kantor BAZNAS Mataram baik itu data primer maupun data skunder. Pengumpulan data tersebut diproses menggunakan motode AHP sehingga hasil perhitungan yang didapatkan berupa rekomendasi kendaraan yang digunakan dalam mendistribusikan zakat, infak dan sedekah.

\subsection{Analytic Hierarchy Process (AHP)}

Analytic Hierarchy Process merupakan satu bentuk model pengambilan keputusan yang melibatkan multi kriteria untuk mendapatkan prioritas keputusan. Keunggulan AHP dibandingkan model MADM lainny aadalah dapat menganalisis secara simultan dan terintegrasi antara kriteria yang kuantitatif dan kualitatif. Metode ini dikembangkan oleh Saaty (1980) dan digunakan untuk menyelesaikan permasalahan yang kompleks dimana data dan informasi statistic tersedia sangat sedikit. 
Tabel 1. Tingkat Kepentingan

\begin{tabular}{|c|l|}
\hline Nilai & \multicolumn{1}{|c|}{ Interpretasi } \\
\hline 1 & $\mathrm{O}_{\mathrm{i}}$ dan $\mathrm{O}_{\mathrm{j}}$ sama penting \\
\hline 3 & $\begin{array}{l}\mathrm{O}_{\mathrm{i}} \text { sedikit lebih penting } \\
\text { daripada } \mathrm{O}_{\mathrm{j}}\end{array}$ \\
\hline 5 & $\begin{array}{l}\mathrm{O}_{\mathrm{i}} \text { kuat tingkat } \\
\text { kepentingannya daripada } \mathrm{O}_{\mathrm{j}}\end{array}$ \\
\hline 7 & $\begin{array}{l}\mathrm{O}_{\mathrm{i}} \text { Sama kuat tingkat } \\
\text { kepentingannya daripada } \mathrm{O}_{\mathrm{j}}\end{array}$ \\
\hline 9 & $\begin{array}{l}\mathrm{O}_{\mathrm{i}} \text { mutlak lebih penting dari } \\
\text { pada } \mathrm{O}_{\mathrm{j}}\end{array}$ \\
\hline $2,4,6,8$ & nilai-nilai intermediate \\
\hline
\end{tabular}

Melakukan meranking prioritas setiap kriteria berdasarkan matriks perbandingan berpasangan dapat dilakukan menggunakan konsepeigenvector (Saaty, 1980) seperti yang terlihat di bawah ini.

1. Apabila A adalah matriks perbandingan berpasangan, maka vector bobot yang berbentuk, $(A)\left(w^{T}\right)=(n)\left(w^{T}\right)$

dapat diketahui dengan cara:

i. Menormalkan setiap kolom j dalam matriks A, sedemikian hingga:

$\sum_{i} a_{i j}=1$

sebutsebagai A'.

ii. Untuk setiap baris i dalam A', hitunglah nilai rata-ratanya:

$$
w_{i}=\frac{1}{n} \sum_{j} a_{i j}^{\prime}
$$

Dengan $w_{i}$ adalah bobot tujuan ke-i dari vektor bobot.

Misalkan A adalah matriks perbandingan berpasangan, dan $\mathrm{w}$ adalah vector bobot, maka konsistensi dari vector bobot $\mathrm{w}$ dapat diuji sebagai berikut:

a. Hitung: $(\mathrm{A})\left(\mathrm{w}^{\mathrm{T}}\right)$

b. hitunglah $t=\frac{1}{n} \sum_{i=1}^{n}\left(\frac{\text { elemen ke -i pada }(\mathrm{A})\left(\mathrm{w}^{\mathrm{T}}\right)}{\text { elemen ke -i pada } \mathrm{w}^{\mathrm{T}}}\right)$

c. hitunglah indeks konsistensi

d. jika $\mathrm{CI}=0$ maka A konsisten;

$$
\text { jika } \frac{C I}{R I_{n}} \leq 0,1 \text { maka A cukup }
$$

konsisten; dan jika $\frac{C I}{R I_{n}}>0,1 \quad$ maka A sangat

tidak konsisten.

Indeks random RIn = nilai rata-rata $\mathrm{CI}$ yang dipilih secara acak pada A dan diberikan sebagai:

\begin{tabular}{l|lllllll}
$\mathrm{N}$ & 2 & 3 & 4 & 5 & 6 & 7 \\
\hline RIn & 0 & 0,58 & 0,90 & 1,12 & 1,24 & 1,32
\end{tabular}.

Sumber : Sri Kusumadewi, dkk. (Fuzzy MADM, hal.99)

\subsection{Analisa Sistem}

Analisis sistem merupakan penguraian dari suatu sistem yang utuh kedalam bagianbagian komponennya dengan maksud untuk mengidentifikasikan dan mengevaluasi permasalahan-permasalahan, hambatanhambatan yang terjadi dari kebutuhan yang diharapkan sehingga dapat diusulkan perbaikan-perbaikannya. Hal-hal yang dilakukan pada tahap analisis sistem adalah analisis masalah, prosedur yang sedang berjalan, dokumen yang terlibat, analisis pengkodean, analisis kebutuhan fungsional dan kebutuhan nonfungsional meliputi analisis perangkat keras, analisis perangkat lunak serta analisis pengguna.

\subsubsection{Data Flow Diagram(DFD)}

Menjelaskan bagaimana diagram tersebut berjalan sesuai dengan sistem sehingga menghasilkan sebuah informasi. Diagram Konteks pada sistem pemilihan kendaraan ini dapat lihat pada Gambar 2. Di bawah ini.

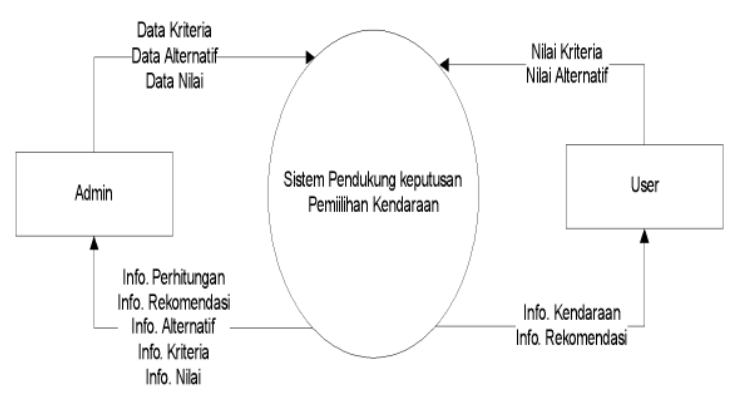

Gambar 2.Diagram Konteks.

Pada digram konteks di atas menjelaskan bahwa admin menambahkan data yang akan digunakan untuk pemilihan kendaraan seperti data kriteria, data alternatif dan data nilai. 
Hasil dari penginputan data tersebut sistem akan memberikan sebuah informasi tentang data alternatif, data kriteria dan data nilai. Penginputkan nilai pada user memberikan penilaian pada data kriteria dan dana alternatif sehingga memberikan solusi berupa rekomendasi.

Pada diagram konteks di atas memberikan gambaran secara umum dari sistem yang dibuat. Untuk mengetahui sistem secara rinci dapat dilihat DFD level 2 pada Gambar 3 di bawah ini.

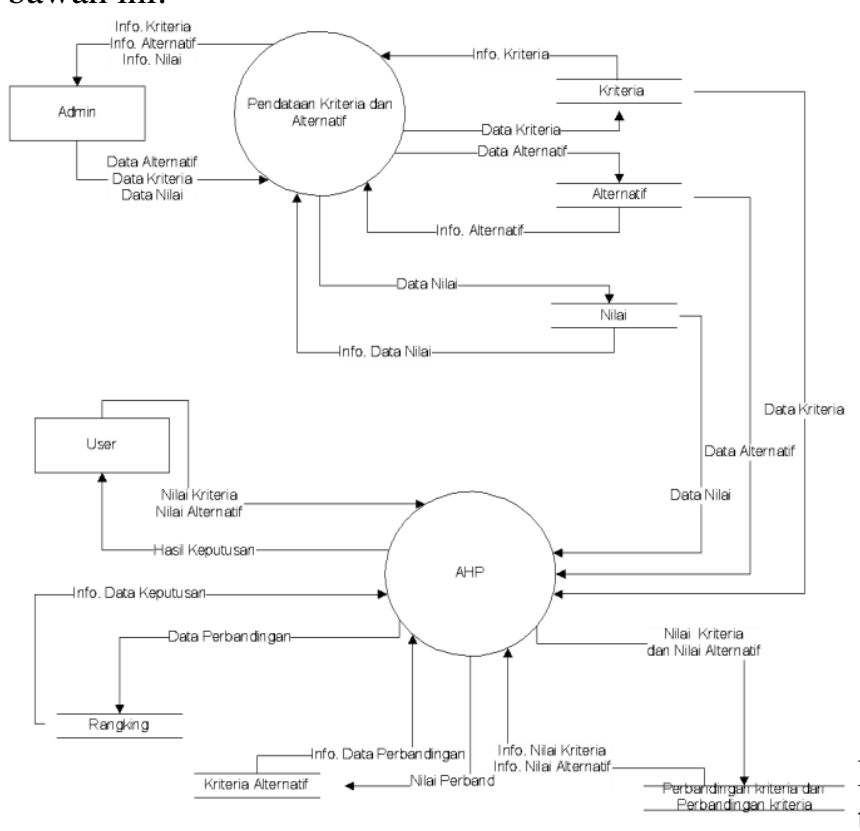

Gambar 3. DFD Level 2.

Pada DFD level 2 di atas memberikan penjelasan bahwa admin menambahkan data berupa data kriteria, data alternatif dan data nilai. Hasil data dari penginputan admin tersebut disimpan oleh database yang akan memberikan informasi data yang sudah masuk. Data kriteria, data alternatif dan data nilai diproses dengan menggunakan metode AHP, sehingga jika user menginputkan nilai kriteria dan nilai alternatif maka setiap nilai yang diberikan akan masuk ke dalam tabel perbandingan kriteria dan perbandingan alternatif, hasil dari tabel masing-masing perbandingan akan memberikan nilai perbandingan kriteria maupun alternatif dan nilai masing-masing perbandingan kriteria dan alternatif dihitung sehingga hasil dari perhitungan data kriteria dan alternatif mendapatkan sebuah rangking nilai rekomendasi yang akan digunakan.

\subsubsection{Database}

Basis data (database) adalah suatu pengorganisasian sekumpulan data yang saling terkait sehingga memudahkan aktivitas untuk memperoleh informasi. Basis data dimaksudkan untuk mengatasi problem pada sistem yang memakai pendekatan berbasis berkas. Rancangan database pada sistem ini dapat digambarkan melalui relasi tabel database yang telihat pada Gambar 4 di bawah ini.

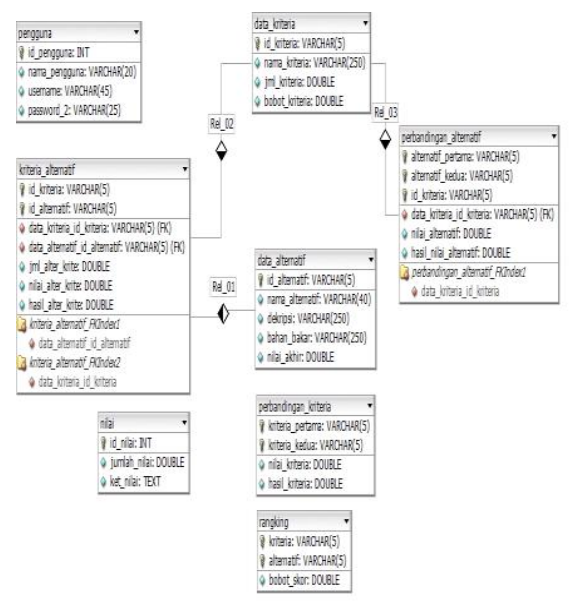

Gambar 4. Relasi Tabel

Pada Gambar 4 di atas memberikan relasi antar table sehingga dapat berkomunikasi dengan table yang lainnya. Tabel pengguna digunakan untuk menyimpan pengguna yang bisa login ke sistem. Tabel nilai memberikan rating nilai yang akan digunakan untuk menilai kriteria dan alternatif. Tabel kriteria memberikan daftar data kriteria apa saja yang menjadi dasar pemilihan kendaraan. Tabel alternatif juga memberikan gambaran tentang data yang menjadi alternatif pilihan. Tabel perbandingan_kriteria untuk memproses perhitungan antar kriteria sehingga menghasilkan nilai konsisten dan tidak konsisten. Tabel perbandingan_alternatif memberikan penjelasan perhitungan antar alternatif dengan dasar kriteria. Tabel kriteria_alternatif proses perhitungan antara nilai tabel alternatif dan tabel kriteria sehingga memberikan rekomendasi nilai yang akan digunakan melalui tabel rangking.

\section{HASIL DAN PEMBAHASAN}

Data Kriteriayang akan dijadikan penilaian pemilihan kendaraan dalam 
mendistribusikan Zakat, Infak dan Sedekah di BAZNAS Kota Mataram terdapat 5 jenis kriteria yang terlihat padaTable 2 di bawah ini.

Tabel 2. Data Kriteria

\begin{tabular}{|l|l|}
\hline Kode & Data Kriteria \\
\hline C1 & Volume \\
\hline C2 & Tahun \\
\hline C3 & Kondisi \\
\hline C4 & Biaya \\
\hline C5 & Performa \\
\hline
\end{tabular}

Setelah menentukan kriteria untuk pemilihan kendaraan, maka langkah selanjutnya menentukan data alternatif yang tersedia di BAZNAS Kota Mataram, terdapat 5 alternatif yang digunakan sebagai pilihan seperti pada Tabel 3 berikut ini.

Tabel 3. Data Alternatif

\begin{tabular}{|l|l|}
\hline Kode & Data Alternatif \\
\hline A1 & Kijang \\
\hline A2 & Avanza \\
\hline A3 & Opencup \\
\hline A4 & Truk \\
\hline A5 & SupraX \\
\hline
\end{tabular}

Data alternatif pada Tabel 3 di atas merupakan jenis kendaraan yang ada di BAZNAS kota, digunakan untuk mendistribusikan Zakat, Infak dan Sedekah ke berbagai wilayah yang ada di Kota Mataram.

\subsection{Perhitungan AHP}

Menghitung perbandingan kriteria dengan kriteria sehingga hasil yang didapatkan dapat menentukan nilai konsisten atau tidak konsisten terhadap nilai yang diberikan oleh user pada setiap kriteria seperti pada Tabel 4 di bawah ini.

Tabel 4. Nilai Kriteria

\begin{tabular}{|l|l|l|l|l|l|}
\hline & Vol & $\begin{array}{l}\text { Tahu } \\
\mathrm{n}\end{array}$ & $\begin{array}{l}\text { Bia } \\
\text { ya }\end{array}$ & $\begin{array}{l}\text { Kon } \\
\text { disi }\end{array}$ & $\begin{array}{l}\text { Perfor } \\
\text { ma }\end{array}$ \\
\hline Vol & 1 & 5 & 4 & 7 & 5 \\
\hline Tahun & 0.2 & 1 & 4 & 3 & 3 \\
\hline Biaya & 0.25 & 0.25 & 1 & 3 & 5 \\
\hline Kondisi & 0.14 & $\begin{array}{l}0.33 \\
3\end{array}$ & $\begin{array}{l}0.3 \\
33\end{array}$ & 1 & 7 \\
\hline $\begin{array}{l}\text { Perform } \\
\text { a }\end{array}$ & 0.2 & $\begin{array}{l}0.33 \\
3\end{array}$ & 0.2 & 0.14 & 1 \\
\hline & 1.79 & $\begin{array}{l}6.91 \\
667\end{array}$ & $\begin{array}{l}9.5 \\
333\end{array}$ & $\begin{array}{l}14.1 \\
429\end{array}$ & 21 \\
\hline
\end{tabular}

Nilai yang diberikan user akan dibagi dengan jumlah nilai masing-masing kriteria sehingga menghasilkan nilai pada Tabel 5 di bawah ini.

Tabel. 5 Nilai Pembagian Kriteria

\begin{tabular}{|l|l|l|l|l|l|l|}
\hline & $\begin{array}{l}\text { Vol } \\
\text { um } \\
\mathrm{e}\end{array}$ & $\begin{array}{l}\text { Tahu } \\
\mathrm{n}\end{array}$ & $\begin{array}{l}\text { Bia } \\
\text { ya }\end{array}$ & $\begin{array}{l}\text { Kond } \\
\text { isi }\end{array}$ & $\begin{array}{l}\text { Perf } \\
\text { orm } \\
\mathrm{a}\end{array}$ & W \\
\hline $\begin{array}{l}\text { Volu } \\
\text { me }\end{array}$ & $\begin{array}{l}0.5 \\
6\end{array}$ & 0.72 & $\begin{array}{l}0.4 \\
2\end{array}$ & 0.50 & 0.24 & $\begin{array}{l}0.4 \\
9\end{array}$ \\
\hline $\begin{array}{l}\text { Tahu } \\
\mathrm{n}\end{array}$ & $\begin{array}{l}0.1 \\
1\end{array}$ & 0.14 & $\begin{array}{l}0.4 \\
2\end{array}$ & 0.21 & 0.14 & $\begin{array}{l}0.2 \\
1\end{array}$ \\
\hline $\begin{array}{l}\text { Biay } \\
\text { a }\end{array}$ & $\begin{array}{l}0.1 \\
4\end{array}$ & 0.03 & $\begin{array}{l}0.1 \\
5\end{array}$ & 0.21 & 0.24 & $\begin{array}{l}0.1 \\
5\end{array}$ \\
\hline $\begin{array}{l}\text { Kon } \\
\text { disi }\end{array}$ & $\begin{array}{l}0.0 \\
8\end{array}$ & 0.05 & $\begin{array}{l}0.0 \\
4\end{array}$ & 0.07 & 0.33 & $\begin{array}{l}0.1 \\
1\end{array}$ \\
\hline $\begin{array}{l}\text { Perf } \\
\text { orma }\end{array}$ & $\begin{array}{l}0.1 \\
1\end{array}$ & 0.05 & $\begin{array}{l}0.0 \\
2\end{array}$ & 0.01 & 0.05 & $\begin{array}{l}0.0 \\
5\end{array}$ \\
\hline & 1 & 1 & 1 & 1 & 1 & 1 \\
\hline
\end{tabular}

Bobot nilai yang sudah didapatkan akan menentukan nilai konsisten dan tidak konsisten terhadap nilai yang diberikan dengan catatan bahwa $\mathrm{CI}<0,1$ maka konsisten dan $\mathrm{CI}>0,1$ maka tidak konsisten. Selanjutnya setelah mendapatkan nilai kriteria, maka perhitungan nilai dari alternatif dapat dilihat seperti yang terdapat pada Tabel 6 di bawah ini.

Tabel 6. Matrik Alternatif

\begin{tabular}{|l|l|l|l|l|l|}
\hline $\begin{array}{l}\text { Volu } \\
\text { me }\end{array}$ & $\begin{array}{l}\text { Kijan } \\
\mathrm{g}\end{array}$ & $\begin{array}{l}\text { Avan } \\
\text { za }\end{array}$ & $\begin{array}{l}\text { Open } \\
\text { cup }\end{array}$ & Truk & $\begin{array}{l}\text { Supr } \\
\text { aX }\end{array}$ \\
\hline $\begin{array}{l}\text { Kija } \\
\text { ng }\end{array}$ & 1 & 3 & 3 & 5 & 6 \\
\hline $\begin{array}{l}\text { Ava } \\
\text { nza }\end{array}$ & 0.33 & 1 & 3 & 6 & 5 \\
\hline $\begin{array}{l}\text { Ope } \\
\text { ncup }\end{array}$ & 0.33 & 0.33 & 1 & 8 & 3 \\
\hline Truk & 0.2 & 0.17 & 0.13 & 1 & 7 \\
\hline $\begin{array}{l}\text { Supr } \\
\text { aX }\end{array}$ & 0.17 & 0.2 & 0.33 & 0.14 & 1 \\
\hline & 2.03 & 4.7 & 7.46 & 20.1 & 22 \\
\hline
\end{tabular}

Perhitungan nilai alternatif pada Tabel 6 di atas menjelaskan bahwa nilai yang diberikan mengambarkan keadaan pada kendaraan yang menjadi alternatif. Nilai yang diberikan oleh user akan dibagi dengan jumlah nilai pada masing-masing alternatif. Sehingga hasil yang diperoleh dari pembagian dapat dilihat pada Tabel 7 di bawah ini. 
Tabel 7 Nilai Pembagian Alternatif

\begin{tabular}{|c|c|c|c|c|c|c|}
\hline & $\begin{array}{l}\text { Kijan } \\
\mathrm{g}\end{array}$ & $\begin{array}{l}\text { Av } \\
\text { anz } \\
\text { a }\end{array}$ & $\begin{array}{l}\text { Op } \\
\text { enc } \\
\text { up }\end{array}$ & $\begin{array}{l}\text { Tru } \\
\mathrm{k}\end{array}$ & $\begin{array}{l}\text { Sup } \\
\text { raX }\end{array}$ & $\mathrm{W}$ \\
\hline $\begin{array}{l}\mathrm{Kij} \\
\text { ang }\end{array}$ & 0.49 & $\begin{array}{l}0.6 \\
383\end{array}$ & $\begin{array}{l}0.4 \\
022\end{array}$ & $\begin{array}{l}0.2 \\
482\end{array}$ & $\begin{array}{l}0.2 \\
724\end{array}$ & 0.5183 \\
\hline $\begin{array}{l}\text { Av } \\
\text { anz } \\
\text { a }\end{array}$ & $\begin{array}{l}0.16 \\
39\end{array}$ & $\begin{array}{l}0.2 \\
128\end{array}$ & $\begin{array}{l}0.4 \\
022\end{array}$ & $\begin{array}{l}0.2 \\
978\end{array}$ & $\begin{array}{l}0.2 \\
273\end{array}$ & 0.1948 \\
\hline $\begin{array}{l}\text { Op } \\
\text { enc } \\
\text { up }\end{array}$ & $\begin{array}{l}0.16 \\
39\end{array}$ & $\begin{array}{l}0.0 \\
710\end{array}$ & $\begin{array}{l}0.1 \\
341\end{array}$ & $\begin{array}{l}0.3 \\
972\end{array}$ & $\begin{array}{l}0.1 \\
364\end{array}$ & 0.1549 \\
\hline $\begin{array}{l}\text { Tru } \\
\mathrm{k}\end{array}$ & $\begin{array}{l}0.09 \\
84\end{array}$ & $\begin{array}{l}0.0 \\
335\end{array}$ & $\begin{array}{l}0.0 \\
168\end{array}$ & $\begin{array}{l}0.0 \\
497\end{array}$ & $\begin{array}{l}0.3 \\
182\end{array}$ & 0.0976 \\
\hline $\begin{array}{l}\text { Su } \\
\text { pra } \\
\text { X }\end{array}$ & $\begin{array}{l}0.08 \\
20\end{array}$ & $\begin{array}{l}0.0 \\
425\end{array}$ & $\begin{array}{l}0.0 \\
447\end{array}$ & $\begin{array}{l}0.0 \\
071\end{array}$ & $\begin{array}{l}0.0 \\
454\end{array}$ & 0.0340 \\
\hline & 1 & 1 & 1 & 1 & 1 & 1 \\
\hline
\end{tabular}

Perhitungan nilai alternatif dapat dihitung satu persatu sesuai dengan jumlah kriteria yang ada. Sehingga hasil yang didapatkan akan dijumlahkan dengan nilai kriteria dan nilai alternatif yang didapatkan sehingga hasil dari penjumlahan nilai yang ada dapat digambar pada Tabel 8 di bawah ini.

Tabel 8. Hasil Akhir

\begin{tabular}{|l|l|}
\hline \multicolumn{1}{|c|}{ Alternatif } & \multicolumn{1}{c|}{ Hasil } \\
\hline Kijang & 0.4998097 \\
\hline Avanza & 0.2003278 \\
\hline Opencup & 0.1648220 \\
\hline Truk & 0.0974747 \\
\hline SupraX & 0.0375657 \\
\hline
\end{tabular}

Hasil yang didapatkan pada Tabel 8 di atas merupakan nilai yang tertinggi untuk dijadikan sebagai bahan rekomendasi dalam pemilihan kendaraan.

\subsection{Prototype}

Sistem yang dihasilkan dimulai dari login ke form utama, dilanjutkan penginputan data kriteria dan data alternatif, memasukkan nilai keanggotaan dari setiap kriteria dan alternatif dengan metode AHP. Hasil pembobotan tersebut dihasilkan bobot prioritas masingmasing kriteria dan alternatif, kemudian dilanjutkan proses perangkingan sehingga menghasilkan informasi berupa nilai rekomendasi kendaraan yang digunakan.

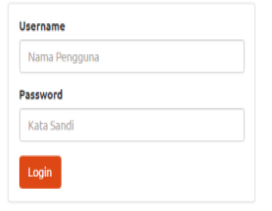

\section{Gambar 5. Form Login}

Pada Gambar 5 di atas menunjukkan proses login ke sistem, jika username dan password yang dimasukkan salah maka sistem memberikan pemberitahuan bahwa username dan password yang anda masukkan salah, tapi jika username dan password yang dimasukkan benar maka sistem akan meneruskan proses selanjutnya.

Data kriteria yang digunakan dalam pemilihan kendaraan seperti yang terlihat pada Gambar 6 di bawah ini.

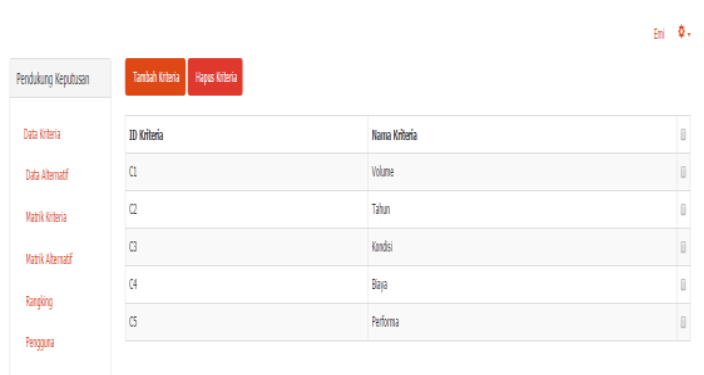

Gambar 6. Form Data Kriteria

Data kriteria pada Gambar 6 di atas digunakan untuk menilai sistem kendaraan yang baik dan cocok dalam memilih jenis kendaraan untuk mendistribusikan zakat infak dan sedekah dari kantor BAZNAS keberbagai wilayah di Kota Mataram.

Sedangkan pada data alternatif tersedia yang digunakan dalam medistribusikan zakat infak dan sedekah seperti yang terlihat pada Gambar 7 di bawah ini.

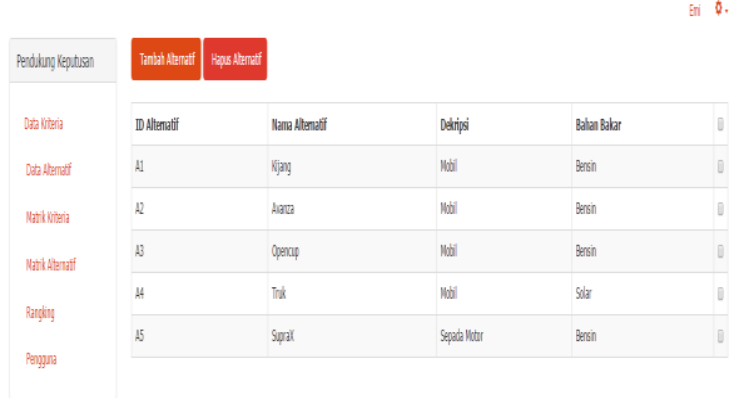

Gambar 7. Form Data Alternatif 
Data alternatif di atas merupakan data kendaraan yang akan dipilih untuk digunakan dalam mendistribusikan zakat, infak dan sedekah ke berbagai wilayah yang ada di kota mataram.

Perhitungan data kriteria dalam menentukan bobot terhadap masing-masing kriteria sehingga akhirnya dapat menentukan nilai konsisten atau tidak konsisten terhadap bobot yang dikasi pada masing-masing kriteria. Hasil perbandingan setiap kriteria setelah dihitung didapatkan nilai seperti pada Gambar 8 di bawah ini.

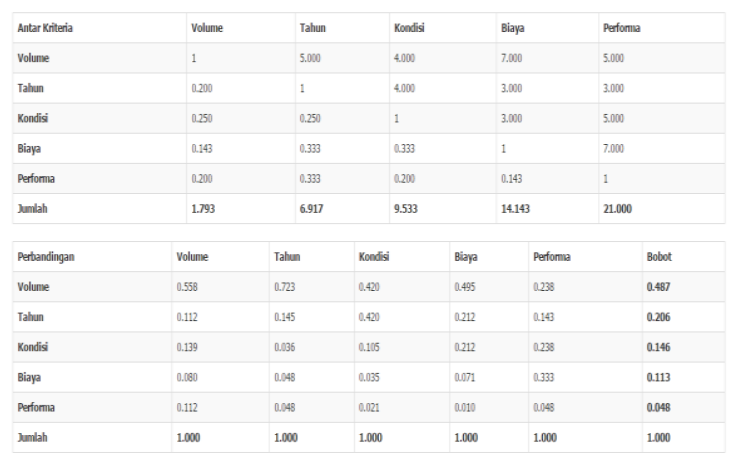

Gambar 8. Nilai Perbandingan Kriteria

Setelah nilai perbandingan kriteria didapatkan, selanjutnya ke tahap perhitungan alternatif dari masing-masing kriteria yang ada. Proses pemberian nilai pada alternatif dari masingmasing kriteria dapat dilihat pada Gambar 9 di bawah ini.

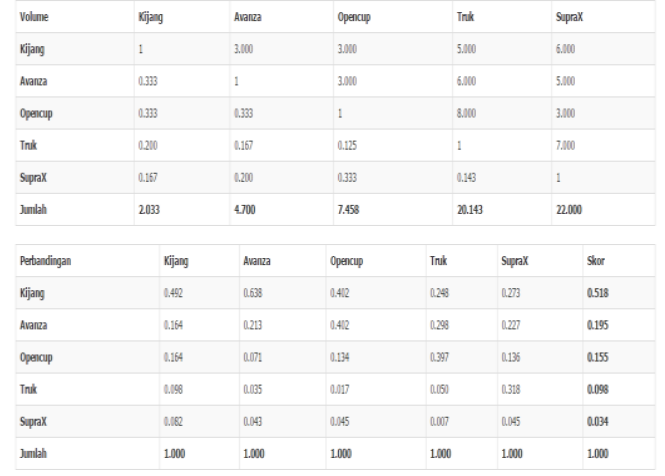

Gambar 9. Form Perbandingan Alternatif Dari Kriteria

Perbandingan alternatif dihitung sesuai dengan jumlah kriteria yang ada, setelah semua data nilai didapatkan maka proses perhitungan nilai kriteria dan nilai alternatif dihitung sehingga menghasilkan nilai rekomendasi. Seperti yang terlihat pada Gambar 10 di bawah ini.

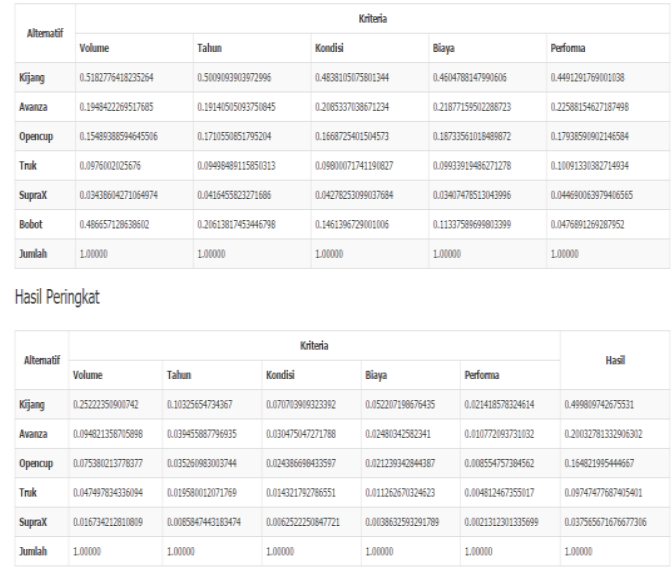

Gambar 10. Perangkingan

Hasil perhitungan metode AHP dari pemilihan kendaraan dalam mendistribusikan zakat, infak dan sedekah ke berbagai wilayah di Kota Mataram terpilih dengan jenis kendaraan Kijang.

Sedangkan untuk melihat daftar pengguna yang dapat mengoperasikan sistem tersebut seperti dilihat pada Gambar 11 di bawah ini.

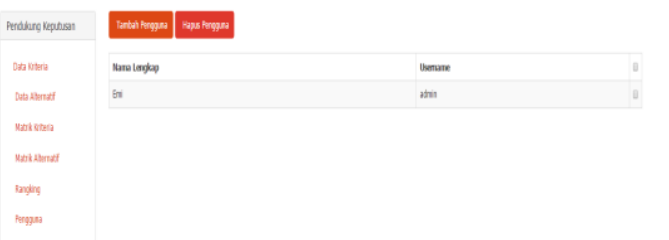

Gambar 11. Pengguna

Pengguna dapat menghapus dan menambah pengguna lebih dari satu. Pengguna disini digunakan untuk login ke sistem ketika sistem baru dimulai beserta password yang sudah didaftarkan sebelumnya.

\section{KESIMPULAN}

Pemilihan kendaraan dengan menggunakan metode AHP dapat sebagai solusi untuk menentukan kendaraan mana yang digunakan dalam mendistribusikan zakat, infak dan sedekah diberbagai daerah yang ada di Kota Mataram. Penilaian yang digunakan dalam pemilihan kendaraan di Kantor BAZNAS Kota Mataram dengan metode AHP ini dari sisi kriteria- kriteria kendaraan seperti Volume, Tahun, Biaya, Kondisi dan performa dari kendaraan yang tersedia di Kantor Baznas 
Mataram. Kendaraan terpilih memiliki nilai tertinggi dari proses perhitungan metode AHP sehingga dari proses pengumpulan data primer maupun skunder menghasilkan kendaraan yang terpilih adalah Kijang skor nilai 0.4998097426 .

\section{SARAN}

Penelitian ini dilakukan di kantor BAZNAS Kota Mataram dalam pemilihan kendaraan untuk mendistribusikan zakat, infak dan sedekah dengan menggunakan metode AHP. Saran untuk pengembang selanjutnya boleh menerapkan metode yang berbeda dan tempat lokasi yang berbeda dengan begitu hasil dan penilaian yang didapatkan sesuai dengan yang diharapkan.

\section{UCAPAN TERIMA KASIH}

Penulis mengucapkan terimakasih kepada DR. Kusrini,M.Kom. selaku dosen yang telah member ilmunya kepada penulis, sehingga penulis bisa mengetahui dan mengerti tentang materi sistem pendukung keputusan.

\section{DAFTAR PUSTAKA}

[1] Harrison, M.; Yang, Z.; Nguyen, T. T.; Kavakeb, S., Wang, J.; Bonsall,S., 2015, a topsis method for vehicle route selection in seaports - a real case analysis of a container terminal in north west europe, IEEE.

[2] Hsieh, Fu-Shiung; Huang, Hao Wei, 2015, decision support for vehicle routing problem with arbitrary pickup/delivery points, IEEE.

[3] Kadir, Abdul 2014, Pengenalan Sistem Informasi Edisi Revisi, ANDI, Yogyakarta.

[4] Kumar Saini, Vinay dan Kumar, Vivek, 2014, AHP, Fuzzy Sets and TOPSIS Based Reliable Route Selection for MANET, IEEE.

[5] Kusumadewi, Sri; Hartati, Sri; Harjoko, Agus; WardoyoRetantyo 2006. Fuzzy Multi-Attribute Decision Making (Fuzzy MADM), GRAHA ILMU.Yogyakarta.

[6] Kusumadewi, Sri dan Purnomo, Hari 2010. Aplikasi Logika Fuzzy untuk Pendukung Keputusan GRAHA ILMU. Yogyakarta. 